\title{
Sixty seconds on ... stay alert
}

\author{
Gareth lacobucci
}

The BMJ

\section{Stay alert for what?}

Covid-19, of course. In a curious move, Boris Johnson's UK government has decided to ditch its clear, unambiguous public information slogan of "stay home, protect the NHS, save lives" in favour of the far less clear and distinctly more ambiguous "stay alert, control the virus, save lives."

\section{Erm ... why?}

The intention is apparently to "broaden the message" to signify that the country is moving into the next phase of the response to the pandemic.

\section{But what does "stay alert" mean?}

According to the government, it means (deep breath) stay at home as much as possible, work from home if you can (but if not, aim to go back to work), limit contact with people outside your own house, keep your distance if you go out (ideally two metres), wash your hands regularly, and continue to self-isolate at home if you have symptoms.

\section{That's a whole lotta subtext}

Too much, say many. With UK infection rates (or "R") still hovering precariously just below one, there are concerns that the new slogan sows confusion at a time when clarity is vital. Susan Michie, a behavioural expert and member of the scientific advisory group for emergencies, warned that it "may be taken as a green light" by many not to stay at home, begin socialising, and partake in activities that could increase the risk of transmission.

\section{Are all UK governments on board with this?}

Far from it. The leaders of Scotland, Wales, and Northern Ireland are all sticking with "stay at home" and keeping previous restrictions in place. Scotland's first minister Nicola Sturgeon said abandoning the original message at such a critical time was potentially "catastrophic" and called the Johnson administration's new slogan "vague and imprecise."

\section{She has a point, doesn't she?}

That it's open to interpretation would be a generous way of putting it (and that's leaving aside the frankly odd mental image that it creates of being "on the lookout" for an invisible virus).

\section{Is this cock up or conspiracy?}

The government is certainly not averse to a public relations gaffe, but there are some suspicions that the change of message is a deliberate ploy to try to shift blame away from ministers and onto the public if rules are breached and infection rates rise again.

\section{What happens if people don't follow the guidance?}

The government said that if people don't adhere to the clear as mud advice, it may need to reimpose tougher restrictions. Stay alert for more on that one. 